\title{
The Effect of Fasting During Ramdan on Endothelial Function
}

\author{
M. A. Khouchab*, L. Chemaou EL Fihri, S. Jourani, N. Charei, M. EL Hattaoui
}

Cardiology Department, Mohamed VI University Hospital, Marrakech, Morocco

DOI: $10.36347 /$ sasjm.2020.v06i04.004

| Received: 14.04.2020 | Accepted: 22.04.2020 | Published: 27.04.2020

*Corresponding author: Mohamed Anas Khouchab

\section{Abstract}

Original Research Article

The endothelium has emerged as the key regulator of vascular homeostasis, in that it has not merely a barrier function but also acts as an active signal transducer for circulating influences that modify the vessel wall phenotype. It has been demonstrated that Dietary patterns may induce a significant impact on vascular reactivity and endothelial function. Different studies demonstrated that healthy dietary lifestyle had a direct effect on the endothelial vascular functions and reduce cardiovascular events (3). However, there is no study that shows clearly the effect of Fasting during Ramadan. The present review exposes the role of flow-mediated dilatation (FMD), most widely used non-invasive ultrasound to assess the effect of fasting during Ramadan in endothelial function and the improvement of cardiovascular functions.

Keywords: Endothélial function, Flow mediated dilatation, Ramadan, nitric oxide.

Copyright @ 2020: This is an open-access article distributed under the terms of the Creative Commons Attribution license which permits unrestricted use, distribution, and reproduction in any medium for non-commercial use (NonCommercial, or CC-BY-NC) provided the original author and source are credited.

\section{INTRODUCTION}

The endothelium has emerged as the key regulator of vascular homeostasis, in that it has not merely a barrier function but also acts as an active signal transducer for circulating influences that modify the vessel wall phenotype [1]. It releases substances that control vascular relaxation and contraction as well as enzymes that control blood clotting, immune function and platelet adhesion. The pioneering experiments of Furchgott and Zawadzki first demonstrated an endothelium-derived relaxing factor that was subsequently shown to be nitric oxide (NO) [2].

Actually, it is known that Alterations in endothelial function appear before the development of morphological changes and it contribute to atherosclerotic lesion development and progression[3].

It has been demonstrated that Dietary patterns may induce a significant impact on vascular reactivity and endothelial function. Ramadan is a lunar month when more than one billion people all over the world fast. Ramadan fasting differs from regular voluntary or experimental fasting by the fact that Muslims do not eat, drink or smoke from dawn to sunset (approximatively $12 \mathrm{~h}$ ). During this month, many changes occur in the quality of food and eating patterns [1].
Different studies demonstrated that healthy dietary lifestyle had a direct effect on the endothelial vascular functions and reduce cardiovascular events [3]. However, there is no study that shows clearly the effect of Fasting during Ramadan.

Appreciation of the role of vascular endothelium throughout the atherosclerotic disease process has led to the development of a range of invasive and non-invasive techniques which study the impact of interventions on endothelial [4,5].

The present review exposes the role of flowmediated dilatation (FMD), most widely used noninvasive ultrasound to assess the effect of fasting during Ramadan in endothelial function and the improvement of cardiovascular functions $[4,6,7]$.

\section{MATERIALS AND METHODS Subjects}

The study included two groups, one group of patients with an endothelial dysfunction and the second with a normal endothelial function. All participants were recruited from Ar-razi hospital university center of Marrakech in Morocco.

Inclusion criteria for the first group were: males and females between 40 and 70 years old with a documented previous history of either coronary artery disease, cerebrovascular, peripheral arterial diseases or 
Diabetes in the past 10 years and who were able to fast during the hole month of Ramadan. Dietary patterns of participants during this period were almost the same including high- carbohydrate diet and foods rich in vitamins and antioxidants such as fruits and vegetables and a low-fatty diet.

Exclusion criteria in this study include pregnancy, breastfeeding, females on menstrual period, patients with acute inflammation or kidney diseases or tumors, patients using medication that contains vasodilation properties such as nitric oxide.

The second group contains subjects with normal endothelial function from 24 to 29 years old. All of them were non-smoker, female out of menstrual period, without any health issues.

\section{STUDY DESIGN}

We conducted a prospective case-controlled study. All subjects were asked to keep their usual lifestyle. The Tobacco use should be stopped at least 6 hours before the test. And all subjects should not eat at least 12 hours before the test.

Every patient in our study ran 3 tests: 1 st one, one week before Ramadan, $2^{\text {nd }}$ one during the third week of Ramadan, and the 3rd one two weeks after Ramadan.

The study included 10 patients with endothelial dysfunction and 10 Subjects with a normal endothelial Function. During the procedure, 2 patients dropped out.
Microvascular endothelial function evaluation:

In our study, we used the technique of Flowmediated dilation (FMD) to evaluate the endothelial function. A number of studies have demonstrated that maximal increase in diameter occurs $45-60 \mathrm{~s}$ after the release of the cuff.

Before initiating an FMD study, the subject should rest for 10 minutes to ensure stable conditions during scanning. The brachial artery was the site of measurement.

Longitudinal images of the brachial artery are obtained with a high- resolution ultrasound probe (usually $7-12 \mathrm{MHz}$ ), while the subject lies in supine position with the arm resting in a comfortable position in a cradle support. The interface between the near and far arterial wall and the vessel lumen has to be clearly defined. Brachial diameter measurements are obtained in end-diastole, identified by the onset of the Rwave[4,8,9]

The sphygmomanometer blood pressure cuff was placed on the forearm, and the brachial artery was imaged above the antecubital fossa. With a placement of the cuff $1-2 \mathrm{~cm}$ distal to the elbow crease.

The duration of cuff occlusion was $5 \mathrm{~min}$. The cuff is inflated to $\geq 50 \mathrm{mmHg}$ above systolic pressure to occlude arterial inflow and this causes ischaemia and subsequent dilatation of downstream resistance vessels by autoregulatory mechanisms. On cuff deflation, reactive hyperemia in the brachial artery occurs and results in vasodilatation if endothelial function is intact.

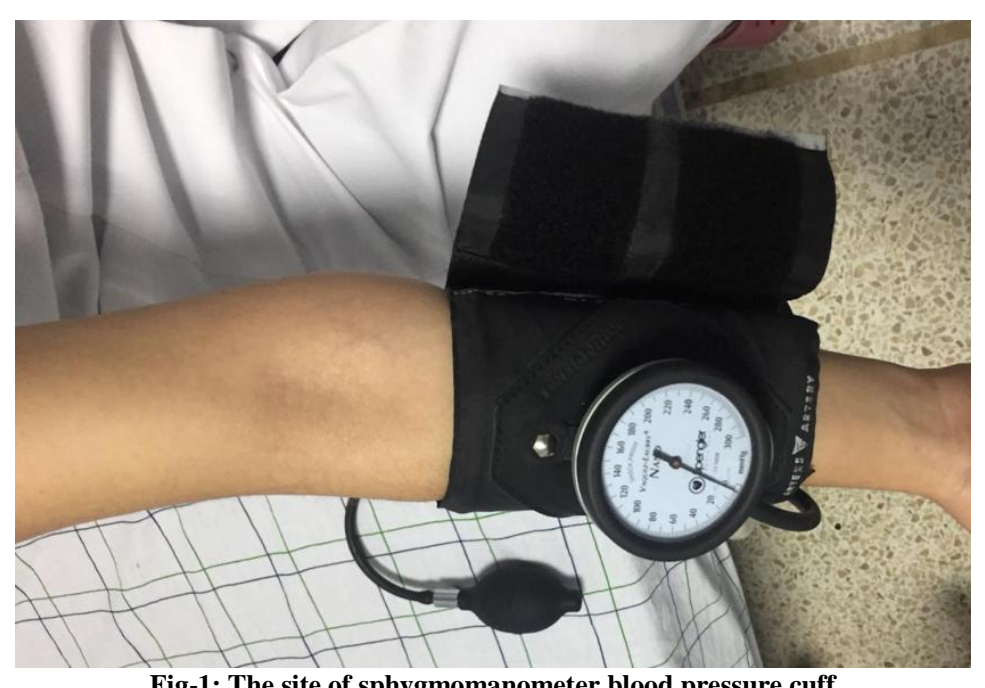

Fig-1: The site of sphygmomanometer blood pressure cuff

Brachial artery diameter was measured 45-60 $\mathrm{S}$ after the release of the cuff. As it's known that this is the maximum of dilatation.

For each test, we measured the percentage of the brachial artery diameter variation. Then we calculated the percentage of variation between the $1^{\text {st }}$ and the last test after finishing Ramadan [4, 10,11].

The same experienced examinator achieved all the tests. The limits of measurement were saved for the following tests so that we didn't have a wrong diameter. 


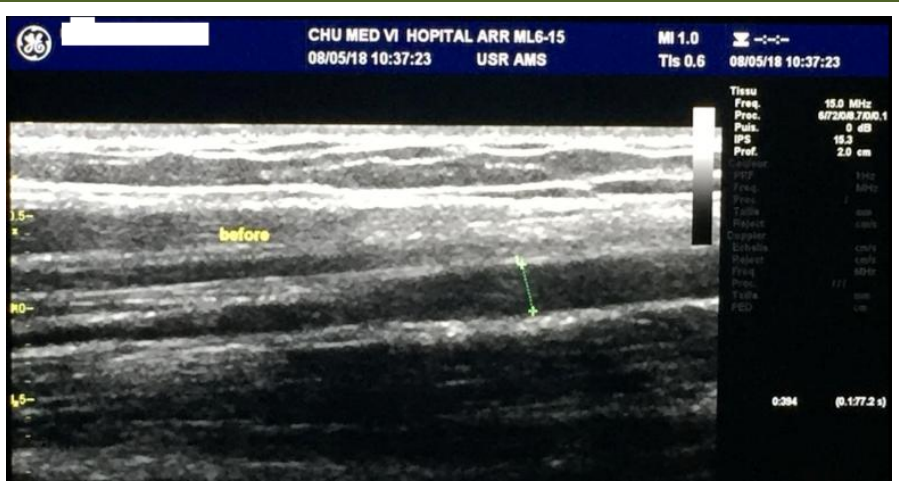

Fig-2: Measurement of brachial artery before occlusion

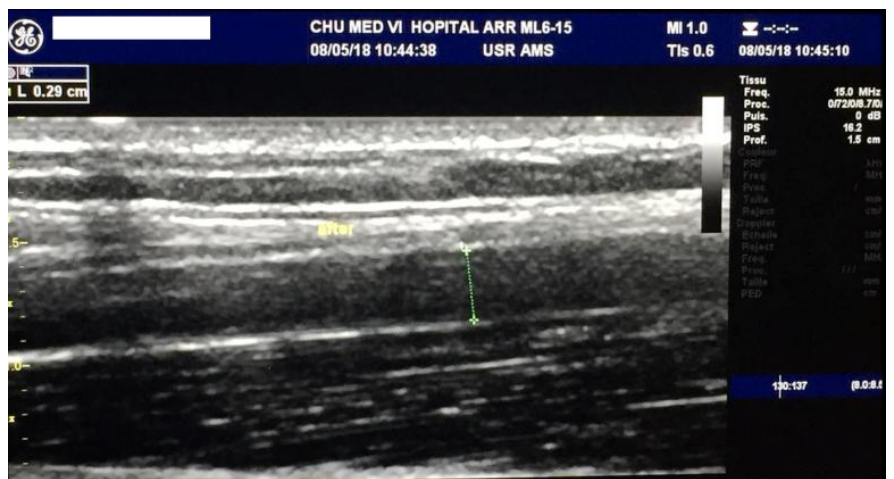

Fig-3: Measurement of brachial artery 40 to 60 seconds after the release of the cuff

\section{RESULTS}

All patients from the first group were between 40 to 70 years old, with a mean age of 58 years old. 7 women and 3 men were included in the first group. study.

2patients dropped out and didn't finish the

The second group was composed from 10 subjects, 4 male and 7 female, aging between 24 and 29 with a mean age of 26 years old.

Fasting during Ramadan caused a significant increase in the percentage of brachial artery Diameter compared to pre-Ramadan percentage.

The variation was highly significant for

- 6 subjects from 8 in the first group (75\%). Mentioning that one person of the two (without a significant variation) had a normal FMD rate in the one week pre-Ramadan test.

- And for 6 from 10 (60\%) for the group with normal function. However, the other 4 people had a normal FMD rate in the one week pre-Ramadan test.

3 Subjects from the group with normal function had an upper Brachial artery bifurcation as an anatomical variation.

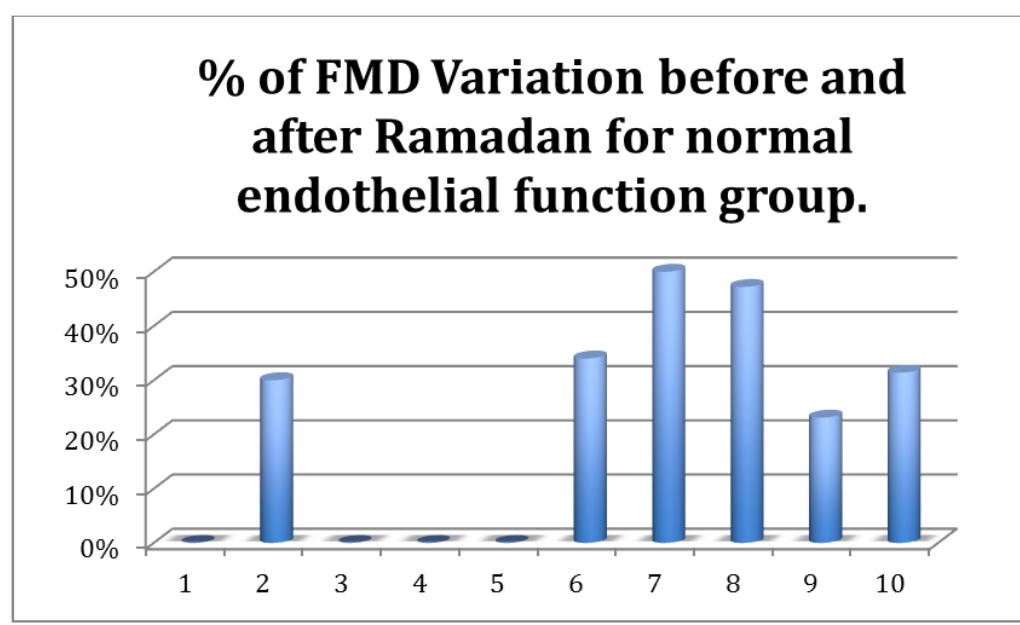

Fig-4: Percentage of FMD Variation before and after Ramadan for normal endothelial function group 


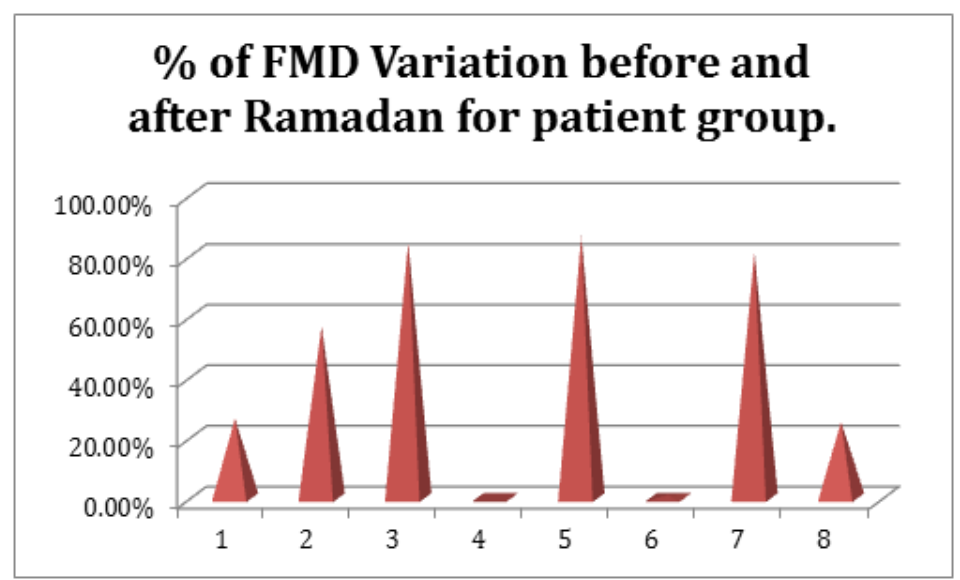

Fig-5: Percentage of FMD Variation before and after Ramadan for patient group

It is clearly shown that Fasting could increase the FMD response, and then an important effect in cardiovascular prognosis as FMD is a direct marker of nitric oxide bio-availability.

\section{DISCUSSION}

Fasting during Ramadan as one of the five major pillars of Islam includes similar instructions for all Muslims all over the world. Dietary habits undergo significant alterations during this month. The global caloric intake is distributed on two meals instead of 3 , mostly composed of carbohydrates. Previous studies showed the effects of Ramadan fasting on weight loss, blood pressure, lipid profiles and other cardiac biomarkers such as high sensitivity $\mathrm{C}$-reactive protein and homocysteine $[3,12,13]$.

Two studies that were performed in Turkey and Albania reported a significant reduction in hospitalization for acute coronary syndrome during the month of Ramadan [3, 14, 15].

B.Yousefi et al., reported from a study in Iran that fasting in Ramadan had a beneficial effects on endothelial function and can modulate cardiovascular risks [3].

This study proved a significant increase in NO metabolite levels in the serum of cardiovascular patients as compared to their pre-Ramadan levels, a lower postRamadan level for asymmetric dimethylarginine (ADMA) [3].

The Belgium study of T. Emaelzadeh and al tested the hypothesis that a prolonged period of intermittent fasting improves endothelial function. After almost a month of 19 hours of daily fasting, both endothelial and non-endothelial microvascular functions were improved, in spite of momentary rises in blood glucose and LDL-cholesterol; Increases in serum triglycerides and blood urea nitrogen hindered thesechanges were mostly apparent at the end of the fasting period. [1].
A recent Study of J. Daniel and al proved that Flow mediated dilation can predict cardiovascular events as a noninvasive test that reflect the level of oxid nitric[16].

We choosed in our study also the FMD as an invasive technique to prove the effects of fasting in Ramadan on endothelial function [17].

Our study showed that fasting during Ramadan can have an impressive effects on Flow mediated dilation, which is related to endothelial function in cardiovascular patients as a direct marker of nitric oxide in the blood vessels and it's vasodilation properties especially in coronary arteries.

\section{CONCLUSIONS}

Fasting during Ramadan may improve endothelial function and can modulate cardiovascular risks. Further studies are needed to confirm the clinical significance of Ramadan fasting on cardiovascular health.

\section{REFERENCES}

1. Esmaeilzadeh F, van de Borne P. Does Intermittent Fasting Improve Microvascular Endothelial Function in Healthy Middle-aged Subjects?. Biol Med Aligarh. 2016; 8: 337.

2. Michael D. Faulx, MD, Andrew T. Wright, RVT, and Brian D. Hoit, MD Cleveland, Ohio ,Detection of endothelial dysfunction with brachial artery ultrasound scanning. Am Heart J. 2003; 145:94351.

3. B Yousefi, Z Faghfoori, N Samad, H Karami, Y Ahmadi, R Badalzadeh, V Shafiei-Irannejad, M Majidinia, $H$ Ghavimi and $M$ Jabbarpour, The effects of Ramadan fasting on endothelial function in patients with cardiovascular diseases, European Journal of Clinical Nutrition. 2014; 68: 835-839

4. Marietta Charakida, Stefano Masi, Thomas F. Luscher, John J.P. Kastelein, and John E. Deanfield, Assessment of atherosclerosis: the role of flow-mediated dilatation, European Heart Journal;2010; 31, 2854-2861. 
5. Halcox JP, Deanfield JE. Endothelial cell function testing: how does the method help us in evaluating vascular status? Acta Paediatr Suppl 2004;93:4854.

6. Anderson TJ, Uehata A, Gerhard MD, Meredith IT, Knab S, Delagrange D, Lieberman EH, Ganz P, Creager MA, Yeung AC. Close relation of endothelial function in the human coronary and peripheral circulations. J Am Coll Cardiol. 1995;26:1235 - 1241 .

7. Takase B, Uehata A, Akima T, Nagai T, Nishioka T, Hamabe A, Satomura K, Ohsuzu F, Kurita A. Endothelium-dependent flow-mediated vasodilation in coronary and brachial arteries in suspected coronary artery disease. Am J Cardiol. 1998;82:1535-1538.

8. Corretti MC, Anderson TJ, Benjamin EJ, Celermajer D, Charbonneau F, Creager MA, Deanfield J, Drexler $\mathrm{H}$, Gerhard-Herman $\mathrm{M}$, Herrington D, Vallance P, Vita J, Vogel R. Guidelines for the ultrasound assessment of endothelial-dependent flow-mediated vasodilation of the brachial artery: a report of the International Brachial Artery Reactivity Task Force. J Am Coll Cardiol. 2002;39:257 - 265 .

9. Donald AE, Halcox JP, Charakida M, Storry C, Wallace SM, Cole TJ, Friberg P, Deanfield JE. Methodological approaches to optimize reproducibility and power in clinical studies of flow-mediated dilation. J Am Coll Cardiol. 2008;51: 1959 - 1964.

10. Doshi SN, Naka KK, Payne N, Jones CJ, Ashton M, Lewis MJ, Goodfellow J. Flow- mediated dilatation following wrist and upper arm occlusion in humans: the con- tribution of nitric oxide. Clin Sci (Lond). 2001;101:629-635.
11. Bots ML, Westerink J, Rabelink TJ, de Koning EJ. Assessment of flow-mediated vasodilatation (FMD) of the brachial artery: effects of technical aspects of the FMD measurement on the FMD response. Eur Heart J. 2005; 26:363-368.

12. AW N, MI O, MR A. The Influence of Ramadan Fasting On Cardiovascular Risk Factors. J Endocrinol Metab; 2010; 1: 1.

13. Nematy M, Alinezhad-Namaghi M, Rashed MM, Mozhdehifard M, Sajjadi SS, Akhlaghi S. Effects of Ramadan fasting on cardiovascular risk factors: a prospective observational study. Nutr J. 2012; 11: 69.

14. Temizhan A, Dönderici Ö, Ouz D, Demirbas B. Is there any effect of Ramadan fasting on acute coronary heart disease events? Int J Cardiol. 1999; 70: 149-153.

15. Burazeri G, Goda A, Kark JD. Religious observance and acute coronary syndrome in predominantly Muslim Albania: a population-based case-control study in Tirana. Ann Epidemiol. 2008; 18: 937-945.

16. Daniel J. Green, Helen Jones, Dick Thijssen, N.T. Cable, Greg Atkinson ,Flow-Mediated Dilation and Cardiovascular Event Prediction Does Nitric Oxide Matter?364 Hypertension March; 2011.

17. Corretti MC, Anderson TJ, Benjamin EJ, Celermajer D, Charbonneau F, Creager MA, Deanfield J, Drexler H, Gerhard-Herman M, Herrington D, Vallance P. Guidelines for the ultrasound assessment of endothelial-dependent flow-mediated vasodilation of the brachial artery: a report of the International Brachial Artery Reactivity Task Force. Journal of the American College of Cardiology. 2002 Jan 16;39(2):257-65. 